\title{
Geopolymer preparation from aluminum dross
}

\section{B. Udvardi, R. Géber, I. Kocserha, L. A. Gömze}

University of Miskolc, Faculty of Material Science, Institute of Ceramics and Polymer Engineering; ubella07@gmail.com,robert.geber@uni-miskolc.hu, istvan.kocserha@uni-miskolc.hu,femgomze@uni-miskolc.hu

In this study aluminum dross based geopolymer samples were made.Geopolymers are inorganic amorphous aluminosilicates, which can be produced byactivating aluminum and silicon-based materials using alkaline activator. It was Davidovits, who studied this material systemand described thechemical structure of geopolymers by polysialtes. In the research work, aluminum dross and sand were used as solid materials. Sodium hydroxide and sodium waterglass were used as an alkali solution for the geopolimerization process. Aftermixing the raw material, the paste was molded and the geopolymer sam- ples were aged for 24 hours at room temperature. Then, the samples were kept for 24 hours at $40{ }^{\circ} \mathrm{C}$ and then again 24 hours at $60^{\circ} \mathrm{C}$. Particle size distributionand chemical elemental composition were determined after the drying of the samples.Material structure measurements were performed by scanning electron microscopy, which resulted in the morphological properties of the samples. Fouriertransforminfrared spectroscopy (FTIR) was used to reveal new phases in geopolymersamples. In addition, density and compression strength of theexperimental samples were determined. 